\title{
Exosomes derived from SW480 colorectal cancer cells promote cell migration in HepG2 hepatocellular cancer cells via the mitogen-activated protein kinase pathway
}

\author{
MITSURU CHIBA $^{1,2}$, NARUMI WATANABE $^{3}$, MIKI WATANABE $^{3}$, MAKI SAKAMOTO $^{3}$, AKIKA SATO $^{3}$, \\ MIZUKI FUJISAKI $^{3}$, SHIORI KUBOTA ${ }^{3}$, SATORU MONZEN ${ }^{2,4}$, ATSUSHI MARUYAMA ${ }^{5}$, \\ NAOKI NANASHIMA $^{1,2}$, IKUO KASHIWAKURA ${ }^{2,4}$ and TOSHIYA NAKAMURA ${ }^{1,2}$

\begin{abstract}
${ }^{1}$ Department of Biomedical Sciences, Division of Medical Life Sciences, Hirosaki University Graduate School of Health Sciences; ${ }^{2}$ Research Center for Biomedical Sciences, Hirosaki University Graduate School of Health Sciences; ${ }^{3}$ Department of Medical Technology, Hirosaki University School of Health Sciences; ${ }^{4}$ Department of Radiological Life Sciences, Division of Medical Life Sciences, Hirosaki University Graduate School of Health Sciences, Hirosaki, Aomori 036-8564; ${ }^{5}$ Department of Stress Response Science, Hirosaki University Graduate School of Medicine, Hirosaki, Aomori 036-8562, Japan
\end{abstract}

Received October 1, 2015; Accepted November 4, 2015

DOI: 10.3892/ijo.2015.3255

\begin{abstract}
Exosomes are membrane-derived extracellular vesicles that have recently been recognized as important mediators of intercellular communication. In the present study, we investigated the effects of exosomes derived from SW480 colorectal cancer cells in recipient HepG2 hepatocellular cancer cells. We demonstrated that SW480-derived exosomes were taken up by the recipient HepG2 cells via dynamin-dependent endocytosis and were localized to the HepG2 lysosomes. In addition, SW480-derived exosomes induced the phosphorylation of extracellular signal-regulated kinase (ERK)1/2 following their uptake into HepG2 cells. Of note, these changes occurred during the early phase after exosome treatment. Furthermore, SW480-derived exosomes promoted the migration of recipient HepG2 cells in a wound-healing assay, which was suppressed by pretreatment with U0126, an upstream inhibitor of ERK1/2. These results indicated that SW480-derived exosomes activated a classical mitogen-activated protein kinase pathway in recipient HepG2 cells via dynamin-dependent endocytosis and subsequently enhanced cell migration by ERK1/2 activation. Our results provide new insights into the regulation of cellular functions by exosomes.
\end{abstract}

Correspondence to: Dr Mitsuru Chiba, Department of Biomedical Sciences, Division of Medical Life Sciences, Hirosaki University Graduate School of Health Sciences, 66-1 Hon-cho, Hirosaki, Aomori 036-8564, Japan

E-mail: mchiba32@hirosaki-u.ac.jp

Key words: exosomes, SW480 colorectal cancer, HepG2 hepatocellular cancer, extracellular signal-regulated kinases $1 / 2$, cell migration, endocytosis

\section{Introduction}

Exosomes are extracellular vesicles that are $40-200 \mathrm{~nm}$ in diameter and are constitutively released from most cell types, including epithelial cells (1), endothelial cells (2), cancer cells (3), dendritic cells (4), mesenchymal stem cells (5), and B lymphocytes (6). Exosomes, initially observed in differentiating reticulocytes three decades ago (7), have recently been identified to perform several important functions as mediators of intercellular communication. Valadi et al reported that exosomes containing mRNAs and miRNAs could be delivered to other cells (8). In addition, Zhang et al demonstrated that microvesicles derived from human monocytic THP-1 cells delivered miR-150 to human endothelial HMEC-1 cells, in which elevated exogenous miR-150 effectively reduced c-myb expression and enhanced cell migration (9). In general, exosomes derived from cancer cells are considered to induce cancerous malignant alterations in recipient cells, such as cell proliferation, extracellular matrix remodelling, cell migration, and angiogenesis (10-12). However, exosomelike nanoparticles derived from cancer cells have also been shown to induce apoptosis in other cancer cell types (13). We have previously shown that exosomes derived from the colorectal cancer cell line SW480, were taken up by the HepG2 hepatocellular cancer cells and A549 lung cancer cells (14). However, the detailed functions of SW480-derived exosomes are not well understood; therefore, we further investigated the effects of SW480-derived exosomes on recipient HepG2 cells.

In the present study, we showed that the uptake of SW480-derived exosomes by HepG2 cells occurred by dynamin-dependent endocytosis, and these exosomes were localized to the lysosomes in HepG2 cells. In addition, SW480-derived exosomes promoted the migration of HepG2 cells via the activation of a classical mitogen-activated protein 
(MAP) kinase pathway. In summary, our results suggested that exosomes derived from cancer cells were able to induce functional changes in other cancer cell types.

\section{Materials and methods}

Cell lines and culture. The human colorectal cancer SW480 cells (CCL-228) were purchased from the American Type Culture Collection (ATCC, Manassas, VA, USA). The human hepatocellular cancer HepG2 cells (JCRB1054) were purchased from the Health Science Research Resources Bank (Osaka, Japan). SW480 cells were cultured in RPMI-1640 medium (Wako, Tokyo, Japan) supplemented with $10 \%$ fetal bovine serum (FBS) (Life Technologies, Carlsbad, CA, USA), $100 \mathrm{U} / \mathrm{ml}$ of penicillin, and $100 \mu \mathrm{g} / \mathrm{ml}$ of streptomycin. HepG2 cells were cultured in Dulbecco's minimum essential medium (DMEM) (Wako) supplemented with 10\% FBS, $100 \mathrm{U} / \mathrm{ml}$ of penicillin, and $100 \mu \mathrm{g} / \mathrm{ml}$ of streptomycin. Cells were cultured at $37^{\circ} \mathrm{C}$ in a humidified atmosphere with $5 \% \mathrm{CO}_{2}$.

Purification of exosomes from culture supernatants. SW480 cells were plated on $10-\mathrm{cm}$ dishes at a density of $1 \times 10^{6}$ cells per dish in the culture media described above. After $72 \mathrm{~h}$, culture media were discarded, cells were washed three times in serum-free culture medium, and $10 \mathrm{ml}$ of serum-free culture medium was added to each dish. After $48 \mathrm{~h}$, cell culture media were collected, and exosomes were isolated by a multistep centrifugation protocol. Briefly, cell culture media were first centrifuged at $300 \mathrm{xg}$ at $4^{\circ} \mathrm{C}$ for $3 \mathrm{~min}$ to remove floating cells. The cleared supernatants were then centrifuged at $2,000 \mathrm{x} \mathrm{g}$ at $4^{\circ} \mathrm{C}$ for $15 \mathrm{~min}$ followed by centrifugation at $12,000 \mathrm{x} \mathrm{g}$ at $4^{\circ} \mathrm{C}$ for $35 \mathrm{~min}$ to remove cellular debris. The supernatants were filtered using a $0.22-\mu \mathrm{m}$ filter and were collected in new tubes. The filtrates were ultracentrifuged at $120,000 \mathrm{x} \mathrm{g}$ at $4^{\circ} \mathrm{C}$ for $70 \mathrm{~min}$ in an Optima TLX Ultracentrifuge (Beckman Coulter, Brea, CA, USA) to collect exosomes. The exosomal pellets were washed in Dulbecco's phosphate buffered saline [D-PBS(-)] with ultracentrifugation at $120,000 \mathrm{x} \mathrm{g}$ at $4^{\circ} \mathrm{C}$ for $70 \mathrm{~min}$ and were resuspended in D-PBS(-).

Determination of protein concentrations. HepG2 cells treated with SW480-derived exosomes were lysed in M-PER Mammalian Protein Extraction Reagent (ThermoFisher Scientific, Waltham, MA, USA) supplemented with Halt proteinase inhibitor cocktail (ThermoFisher Scientific). The protein concentrations were determined using a Micro BCA Protein Assay kit (ThermoFisher Scientific) and a Benchmark Microplate Reader (Bio-Rad, Hercules, CA, USA), according to the manufacturer's instructions.

Sodium dodecyl sulphate-polyacrylamide gel electrophoresis (SDS-PAGE). Protein samples $(10 \mu \mathrm{g})$ were prepared using $4 \mathrm{X}$ sample buffer $(0.25 \mathrm{~mol} / \mathrm{l}$ Tris- $\mathrm{HCl}, 8 \%$ SDS, $40 \%$ glycerol, $20 \%$ 2-mercaptoethanol, and $0.02 \%$ bromophenol blue, $\mathrm{pH} 6.8$ ) and were boiled at $100^{\circ} \mathrm{C}$ for $5 \mathrm{~min}$ with immediate cooling on ice. Protein electrophoresis was performed using 10\% Mini Protean TGX Precast Gels (Bio-Rad), Precision Plus Protein Dual Color Standards (Bio-Rad), and electrophoresis buffer (25 mM Tris-HCl, $192 \mathrm{mM}$ glycine, and 0.1\% SDS, pH 8.3) at $200 \mathrm{~V}$ and $0.03 \mathrm{~A}$ for $30 \mathrm{~min}$.
Western blotting. Following electrophoresis, proteins in gels were transferred to Trans-Blot Turbo Transfer Pack Mini PVDF membranes (Bio-Rad) using transfer buffer ( $25 \mathrm{mM}$ Tris- $\mathrm{HCl}$, $192 \mathrm{mM}$ glycine, $0.01 \%$ SDS, and $20 \%$ methanol, $\mathrm{pH}$ 8.3) and a Trans-Blot Turbo Transfer System (Bio-Rad) at $25 \mathrm{~V}$ and $2.5 \mathrm{~A}$ for $3 \mathrm{~min}$. Membranes were then washed with TBST buffer ( $25 \mathrm{mM}$ Tris-HCl, $150 \mathrm{mM} \mathrm{NaCl}$, and $0.05 \%$ Tween-20, $\mathrm{pH}$ 7.2) and incubated in the PVDF Blocking Reagent for Can Get Signal (Toyobo, Osaka, Japan) at room temperature for $60 \mathrm{~min}$. After blocking, membranes were incubated in a Can Get Signal Immunoreaction Enhancer Solution 1 (Toyobo) containing the indicated primary antibody at $4^{\circ} \mathrm{C}$ overnight.

The primary antibodies used were as follows: Antiphospho-c-RAF (Ser338) rabbit monoclonal antibody [\#9427, Cell Signaling Technology (CST), Danvers, MA, USA], anti-phospho-MEK1/2 (Ser217/221) rabbit monoclonal antibody (\#9154, CST), anti-phospho-ERK1/2 (Thr202/Tyr204) rabbit monoclonal antibody (\#4370, CST), and anti-phosphop90RSK (Ser380) rabbit monoclonal antibody (\#9335, CST). Membranes were washed five times for $5 \mathrm{~min}$ with TBST buffer and were incubated at room temperature for $60 \mathrm{~min}$ with an anti-rabbit immunoglobulin $\mathrm{G}$ (IgG) horseradish peroxidase (HRP)-linked antibody (\#7074, CST), prepared in the Can Get Signal Immunoreaction Enhancer Solution 2. Membranes were also washed five times for 5 min each with TBST buffer, and bound antibodies were visualized with an ImmunoStar Zeta chemiluminescence system (Wako). Images were analyzed using ChemiDoc XRS (Bio-Rad) with Quantity One software (Bio-Rad).

RNA isolation. Total RNA from HepG2 cells treated with SW480-derived exosomes were isolated using Isogen II (NipponGene, Tokyo, Japan), according to the manufacturer's instructions.

Microarray analysis. To assess mRNA expression in HepG2 cells treated with SW480-derived exosomes, a two-color mRNA microarray method was used. The mRNAs in HepG2 cells exposed to $10 \mathrm{ng} / \mu \mathrm{l}$ of exosomes for $24 \mathrm{~h}$ and control HepG2 cells were labeled with an Amino Allyl aRNA kit (Life Technologies) using either a Cy3 or a Cy5 mono-reactive dye (GE Healthcare, Buckinghamshire, UK). Microarray analysis was performed using a Toray mRNA microarray system (Toray, Tokyo, Japan). Toray 3D-Gene Human mRNA Oligo chips were hybridized with Cy3- or Cy5-labeled mRNAs in a hybridization solution at $37^{\circ} \mathrm{C}$ for $16 \mathrm{~h}$ using a hybridization oven and were washed in a wash buffer according to the manufacturer's instructions. The images of fluorescent signals on the chips were acquired using a Toray 3D-Gene Scanner 3000. The gene expression profiles were examined using the GeneSpring GX12.6 software (Agilent Technologies, Santa Clara, CA, USA). The Ingenuity Pathway Analysis (IPA; Qiagen, Redwood City, CA, USA) was used to predict the change of function in HepG2 cells treated with SW480derived exosomes.

PKH67 labeling of exosomes and exosomal uptake into recipient cells. SW480-derived exosomes were collected from $100 \mathrm{ml}$ of culture medium as described above. Exosomes were labeled using PKH67 Fluorescent Cell 
Linker kits (Sigma-Aldrich, St. Louis, MO) according to the manufacturer's instructions, with minor modifications in the washing steps. After washing, exosomal pellets were resuspended in $700 \mu \mathrm{l}$ of Diluent $\mathrm{C}$ (exosomal solution). One microliter of PKH67 dye was diluted in $250 \mu \mathrm{l}$ of Diluent C to prepare the PKH67 solution, and $250 \mu \mathrm{l}$ of the exosomal solution and $250 \mu \mathrm{l}$ of the PKH67 solution were mixed in a $4.7 \mathrm{ml}$ centrifuge tube. Samples were then gently mixed for $4 \mathrm{~min}$, and $4.2 \mathrm{ml}$ of $1 \%$ bovine serum albumin was added to bind any excess PKH67 dye. PKH67-labeled exosomes were ultracentrifuged at $120,000 \mathrm{x}$ g at $4^{\circ} \mathrm{C}$ for $70 \mathrm{~min}$ in an Optima TLX Ultracentrifuge. Exosomal pellets were washed three times in D-PBS(-) by ultracentrifugation at $120,000 \mathrm{x}$ g at $4^{\circ} \mathrm{C}$ for $70 \mathrm{~min}$ and resuspended in $500 \mu \mathrm{l}$ of D-PBS(-).

To examine the uptake of exosomes into recipient HepG2 cells, HepG2 cells were plated in 8 -well chamber slides at a density of $1 \times 10^{4}$ cells per well. After $24 \mathrm{~h}$, the slides were washed three times in D-PBS(-), and DMEM containing either PKH67-labeled exosomal solution or control solution was added into each well, with or without dynasore, a dynamin inhibitor (Sigma-Aldrich). Cells were cultured for 0, 30, $120 \mathrm{~min}$, or $24 \mathrm{~h}$ at $37^{\circ} \mathrm{C}$ in a humidified atmosphere with $5 \% \mathrm{CO}_{2}$. The slides were washed three times in D-PBS(-) and fixed with $3.7 \%$ formaldehyde solution at room temperature for $10 \mathrm{~min}$. Slides were then washed three times in D-PBS(-). After the staining of nuclei using a ProLong Gold Antifade Reagent with 4',6-diamidino-2-phenylindole (DAPI; Life Technologies), the slides were covered with coverslips and visualized under a confocal laser scanning microscope (LSM710; Carl Zeiss, Oberkochen, Germany).

Immunofluorescence staining. Immunofluorescence staining was performed to determine intracellular protein localization. HepG2 cells were plated at a density of $5 \times 10^{4}$ cells per well in 12-well plates with coverslips. SW480-derived exosomes were added to HepG2 cells and were incubated for 0,30 or $120 \mathrm{~min}$ at $37^{\circ} \mathrm{C}$ in a humidified atmosphere with $5 \% \mathrm{CO}_{2}$. After incubation, the coverslips were washed three times in TBS buffer (25 mM Tris- $\mathrm{HCl}$ and $150 \mathrm{mM} \mathrm{NaCl}, \mathrm{pH} 7.2)$ and fixed with $3.7 \%$ formaldehyde solution. The coverslips were then washed three times in TBS buffer and incubated with a membrane-permeation solution $(0.2 \%$ Triton X-100 in TBS buffer) at room temperature for $5 \mathrm{~min}$. After washing three times in TBS buffer, the coverslips were incubated in an Image-iT FX signal enhancer solution (Life Technologies) at room temperature for $30 \mathrm{~min}$. Next, the coverslips were incubated with the Can Get Signal Immunostain Solution A (Toyobo) containing a primary rabbit monoclonal antibody raised against a lysosome-associated membrane protein 1 (LAMP1) (\#9091, CST) and with a 1:100 dilution at room temperature for $60 \mathrm{~min}$. The coverslips were washed five times with TBS buffer and incubated at room temperature for 60 min with an anti-rabbit IgG Alexa Fluor 647-conjugated secondary antibody (\#4414, CST) prepared in the Can Get Signal Immunostain Solution B with a 1:1000 dilution. The coverslips were washed five times with TBS buffer, and the nuclei were stained using a ProLong Gold Antifade Reagent with DAPI. Finally, stained cells were visualized under a confocal laser scanning microscope LSM710 (Carl Zeiss) under the same conditions.
Reverse transcription-quantitative polymerase chain reaction $(R T-q P C R)$. To investigate intracellular mRNA expression in HepG2 cells treated with SW480-derived exosomes, cDNAs derived from total RNA isolated from HepG2 cells were synthesized using a High Capacity cDNA Reverse Transcriptase kit (Life Technologies), according to the manufacturer's instructions. qPCR for mRNAs was performed using a 2X Power SYBR Green Master Mix (Life Technologies), $10 \mu \mathrm{M}$ of forward and reverse primer pairs, and the StepOne Plus Real-Time PCR system (Life Technologies) using the following conditions: $10 \mathrm{~min}$ at $95^{\circ} \mathrm{C}$, followed by 40 cycles each of $95^{\circ} \mathrm{C}$ for $15 \mathrm{sec}$ and $60^{\circ} \mathrm{C}$ for $60 \mathrm{sec}$. GAPDH was used for internal corrections.

Wound-healing assay. HepG2 cells were seeded at a density of $1 \times 10^{5}$ cells per well in 24-well flat-bottomed microplates and were cultured to $90 \%$ confluency at $37^{\circ} \mathrm{C}$ in a humidified atmosphere with $5 \% \mathrm{CO}_{2}$. A thin scratch (wound) was made in the central area using pipette tips, and cells were carefully washed three times with serum-free DMEM. An exosomal solution suspended in DMEM was then added to the culture media of scratched HepG2 cells. Wound closure was monitored by light microscopy, and images were acquired at 0,12 , 24,48 and $72 \mathrm{~h}$ post-scratching. The wound width $(\mu \mathrm{m})$ was measured to assess wound healing.

Statistical analysis. Results are provided as mean \pm standard error of the mean (SEM). Student's t-test was used to compare the results of two groups, and one-way analysis of variance (ANOVA) was used to compare the results of more than two groups. If significant differences were observed by ANOVA, post-hoc pair-wise comparisons were determined using Tukey's test. The level of statistical significance was set at $\mathrm{p}<0.05$.

\section{Results}

Exosomes enter recipient cells via dynamin-dependent endocytosis and subsequently localize to the lysosomes. We have previously shown that SW480-derived exosomes were taken up into recipient HepG2 cells (14). Herein, we started our investigation with determining whether endocytic mechanisms were associated with the uptake of these exosomes. In addition, we determined the localization of these exogenous exosomes in HepG2 cells.

SW480-derived exosomes were labeled with the PKH67 dye (green fluorescence) and added to the culture media of HepG2 cells to determine their uptake with confocal laser scanning microscopy (Fig. 1A). As seen in Fig. 1B, the green fluorescence was detected in HepG2 cells $24 \mathrm{~h}$ after the addition of PKH67-labeled exosomes. To determine whether the exosomes were taken up via endocytosis, PKH67-labeled exosomes were added to the culture media of HepG2 cells in the presence of increasing doses of dynasore. We observed that the green fluorescence in HepG2 cells was decreased in a dose-dependent manner (Fig. 1C). This suggested that dynamin-dependent endocytosis, including clathrin-mediated endocytosis, was involved in the uptake of SW480-derived exosomes into HepG2 cells.

To determine the intracellular localization of these exosomes in HepG 2 cells, we investigated the colocaliza- 
A

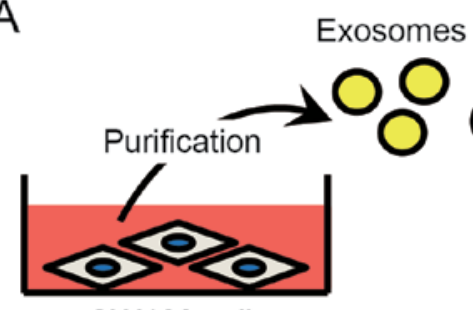

SW480 cells

C

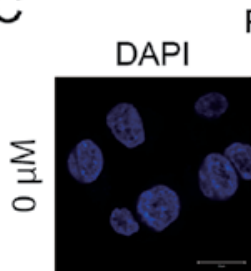

PKH67-labeled exosomes
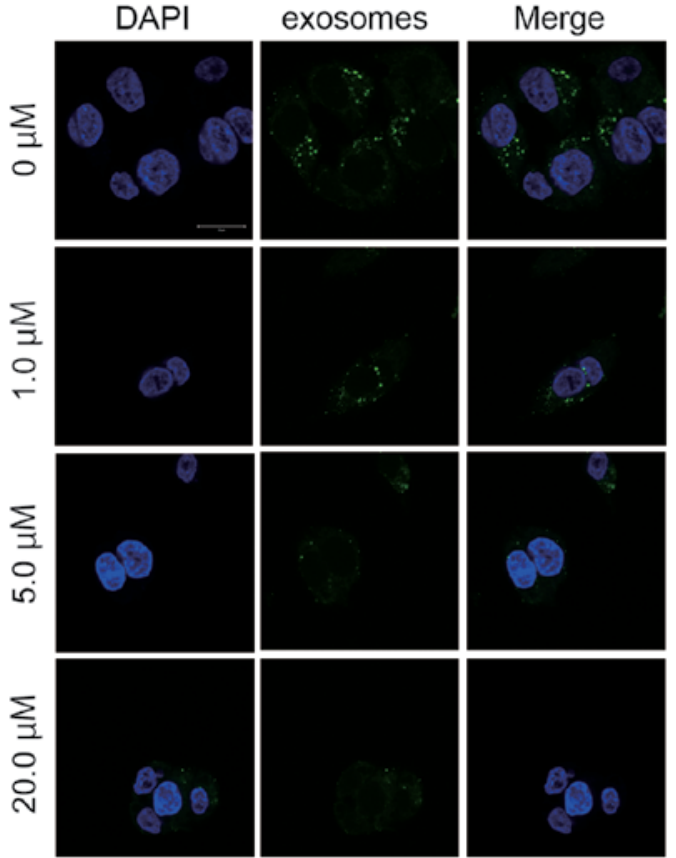

PKH67 dye labeling

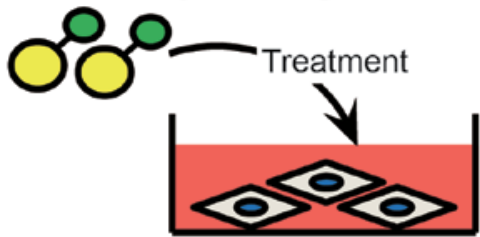

HepG2 cells
B

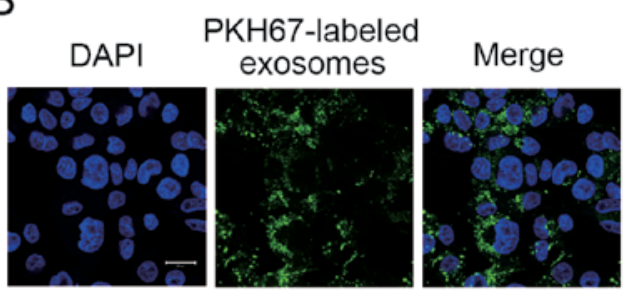

$\mathrm{D}$

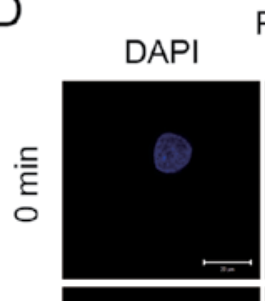

PKH67-labeled exosomes

LAMP1
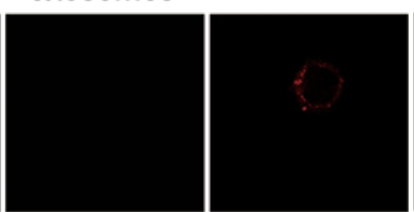

Merge

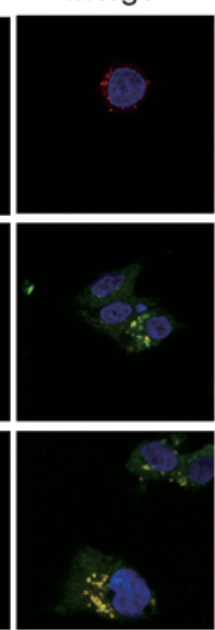

Figure 1. SW480-derived exosomes are taken up into HepG2 cells via dynamin-dependent endocytosis and localize to lysosomes. (A) Schematic diagram of the experimental procedures. SW480-derived exosomes labeled with the PKH67 dye were added to the culture media of HepG2 cells. (B) Visualization of HepG2 cells incubated with PKH67-labeled exosomes (green fluorescence) for $24 \mathrm{~h}$ using confocal laser microscopy. Note the green fluorescent signals in HepG2 cells. Nuclei are labeled with DAPI. (C) Assessment of PKH67-labeled exosomal uptake in HepG2 cells treated with dynasore, a dynamin inhibitor, at final concentrations of $0,1.0,5.0$ or $20.0 \mu \mathrm{M}$ for $30 \mathrm{~min}$ with confocal laser microscopy. (D) Localization of PKH67-labeled exosomes in HepG2 cells at 0,30 or $120 \mathrm{~min}$ after the addition of labeled exosomes to the culture media by confocal laser microscopy. The cultures were also stained by immunofluorescence for LAMP1, a lysosome marker, and an Alexa Fluor 647-conjugated secondary antibody. Scale bar represents $20 \mu \mathrm{m}$.

tion of PKH67-labeled exosomes with the lysosomal marker LAMP1, in HepG2 cells. The colocalization of PKH67-labeled exosomes with LAMP1 was observed at 30 min after PKH67labeled exosomes were added to HepG2 cell culture medium, and the colocalization was maximal at $120 \mathrm{~min}$ (Fig. 1D). These results suggested that the exosomes taken up by HepG2 cells localized to the lysosomes within $30 \mathrm{~min}$ and that some of these exosomes were digested in HepG2 cells.

Exosomes enhance recipient cell migration via the classical MAP kinase pathway. Exosomes have been shown to transfer information between cells (8). To examine the effects of SW480-derived exosomes on recipient HepG2 cell phenotypes, HepG2 cells were observed under a light microscope (Fig. 2A). At $72 \mathrm{~h}$ after treatment with $10 \mathrm{ng} / \mu \mathrm{l} \mathrm{SW} 480$-derived exosomes, there was an observable change in the morphology of HepG2 cells compared with that of untreated HepG2 cells (Fig. 2B). This suggested that SW480-derived exosomes induced functional changes in recipient cells, such as those associated with cellular morphology.
Zhu et al demonstrated that exosomes derived from mesenchymal stem cells promoted tumor growth via the activation of the MAP kinase pathway (12). Therefore, we investigated the phosphorylation status of the components of the MAP kinase pathway following the introduction of $10 \mathrm{ng} / \mu \mathrm{l} \mathrm{SW} 480$-derived exosomes into the culture media of HepG2 cells by western blotting. As seen in Fig. 2C, SW480-derived exosomes led to increases in the expression of phospho-c-RAF, phospho-MEK1/2, phospho-ERK1/2, and phospho-p90RSK in HepG2 cells and indicated that SW480derived exosomes led to the activation of a classical MAP kinase pathway in HepG2 cells.

To determine whether the activation of the classical MAP kinase pathway induced by treatment with exosomes was due to their uptake, we assessed phospho-ERK1/2 protein expression in cells that were treated with $10 \mathrm{ng} / \mu \mathrm{l}$ exosomes in the presence or absence of dynasore. We observed increased ERK1/2 phosphorylation in cells treated with exosomes in the absence of dynasore, which was inhibited in cultured coincubated with $20.0 \mu \mathrm{M}$ dynasore (Fig. 2D). These results indicated that 
A

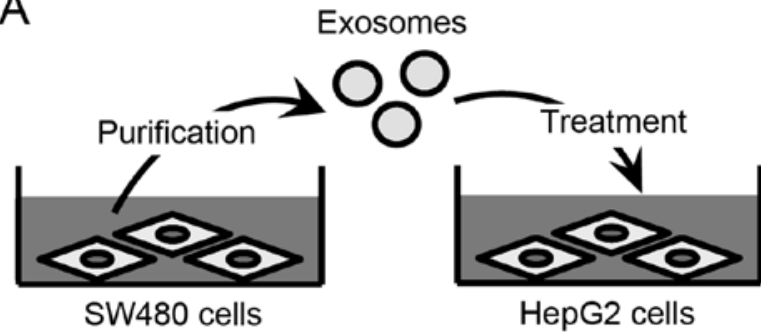

B

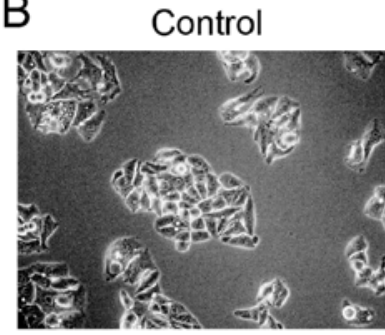

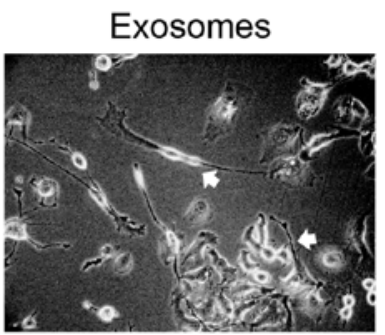

C

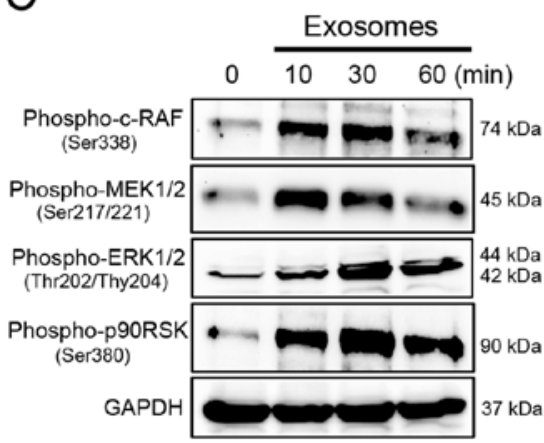

D

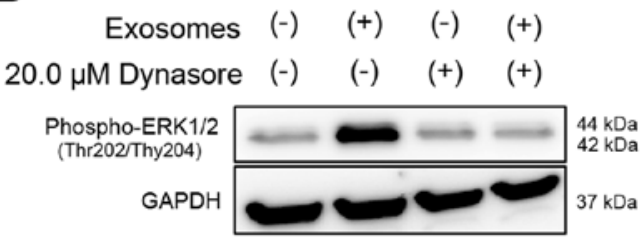

E Exosomes (-) $10.0 \mu \mathrm{M} \cup 0126$
$(-)$

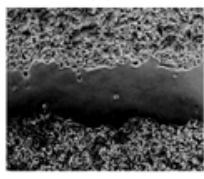

(+)

(-)

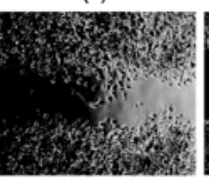

$(-)$

$(+)$
$(+)$

$(+)$
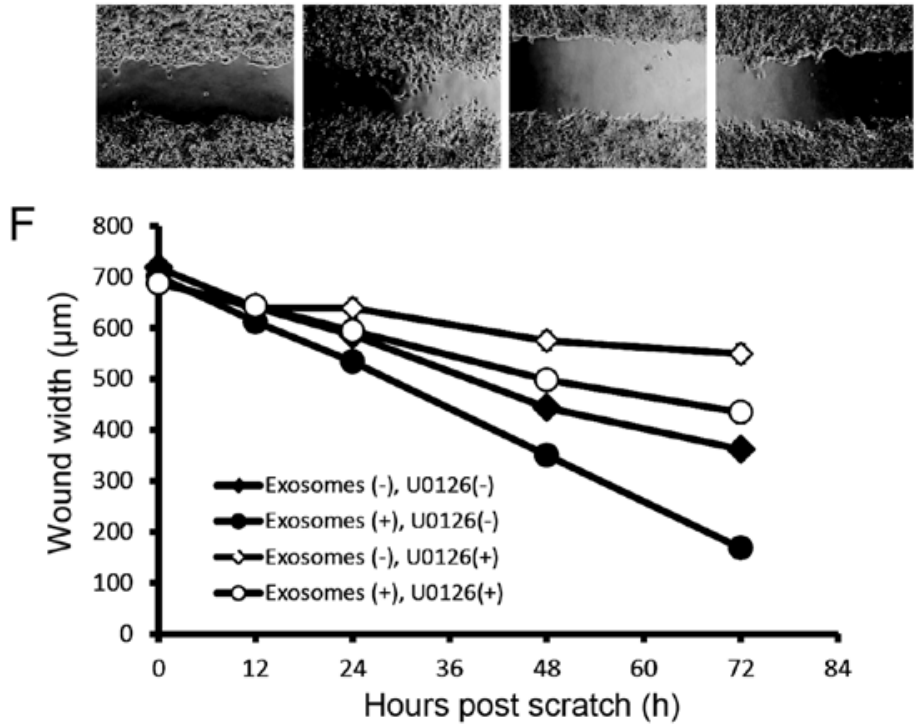

Figure 2. SW480-derived exosomes induce HepG2 cell migration via the classical mitogen-activated protein (MAP) kinase pathway. (A) Illustration of the experimental procedures. SW480-derived exosomes were added to the culture media of HepG2 cells in 12 -well plates and incubated for 72 h. (B) The morphology of HepG2 cells after incubation with SW480-derived exosomes. (C) Western blotting was used to assess changes in MAP kinase signaling by the detection of phospho-c-RAF, phospho-MEK1/2, phospho-ERK1/2, phospho-p90RSK, and GAPDH in HepG2 cells incubated with SW480-derived exosomes for $0,10,30$ or $60 \mathrm{~min}$. (D) Assessment of ERK1/2 phosphorylation in response to dynasore treatment and/or SW480-derived exosomes for 30 min. (E and F) Exosome-induced cell migration as assessed by the wound-healing assay. (E) Photomicrograph of wound width in HepG2 cultures $48 \mathrm{~h}$ after scratching. Cell migration was assessed in cultures incubated with U0126, MEK1/2 inhibitor, and/or SW480-derived exosomes. (F) Wound width ( $\mu$ m) at the indicated times after scratching of HepG2 cultures treated with SW480-derived exosomes at a final concentration of $10 \mathrm{ng} / \mu 1 \mathrm{for} 0,12,24,48$ or $72 \mathrm{~h}$. All bars represent mean \pm SEM $(n=7)$. Statistical comparisons were determined by one-way ANOVA with Tukey's multiple comparisons post-hoc test.

ERK1/2 phosphorylation was induced by dynamin-dependent exosomal endocytosis.

In previous studies, the MAP kinase pathway has been shown to be involved in cell growth and differentiation as well as in cell migration $(15,16)$. To determine whether the activation of the classical MAP kinase pathway by SW480-derived exosomes altered cell migration, we used a wound-healing assay, in which SW480-derived exosomes were added to the culture media in the presence or absence of the MEK1/2 inhibitor U0126. In this model, the migration of HepG2 cells was significantly enhanced by exosome treatment for 24,48 , and $72 \mathrm{~h}$ compared with untreated controls at each time point ( $\mathrm{p}<0.05, \mathrm{p}<0.01$ and $\mathrm{p}<0.01$, respectively) (Fig. 2E and F), indicating that SW480-derived exosomes induced the migration of HepG2 cells.

In addition, treatment with $10.0 \mu \mathrm{M}$ U0126 for 24,48 , and $72 \mathrm{~h}$ significantly inhibited the migration of HepG2 cells compared with untreated controls at each time point in the absence of SW480-derived exosomes $(\mathrm{p}<0.05, \mathrm{p}<0.01$ and $\mathrm{p}<0.01$, respectively). These results indicated that the classical MAP kinase pathway was involved in HepG2 cell migration. Noteworthy, we observed that exosome-treated HepG2 cell migration was significantly inhibited in U0126treated cultures after 24,48 , and $72 \mathrm{~h}$ compared with the migration in U0126-untreated cultures $(\mathrm{p}<0.05, \mathrm{p}<0.01$ and $\mathrm{p}<0.01$, respectively), indicating that the classical MAP kinase pathway was involved in the enhancement of exosomemediated HepG2 cell migration. Finally, we assessed the impact of SW480-derived exosomes on U0126-treated HepG2 cells and observed that HepG2 cell migration was significantly enhanced in cultures treated with exosomes for 48 and $72 \mathrm{~h}$ compared with HepG2 cell migration in cultures that were not exposed to exosomes ( $\mathrm{p}<0.01$, for both time points). These results suggested that the exosome-mediated induction of cell migration involves a second pathway distinct from the classical MAP kinase pathway.

Exosomes induce changes in gene expression in the recipient HepG 2 cells. To investigate the potential effects of SW480derived exosomes on gene expression in HepG2 cells, we 

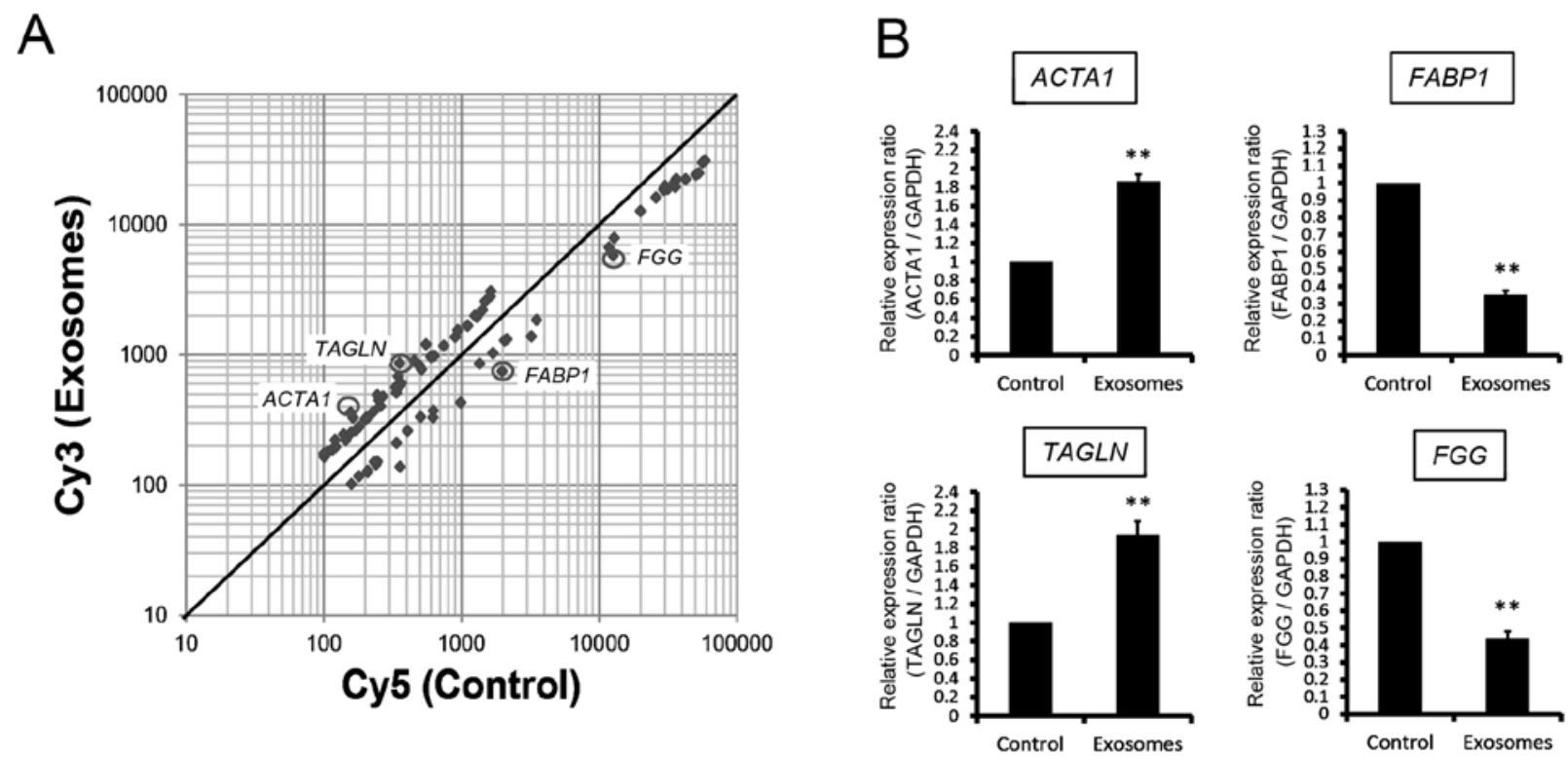

C

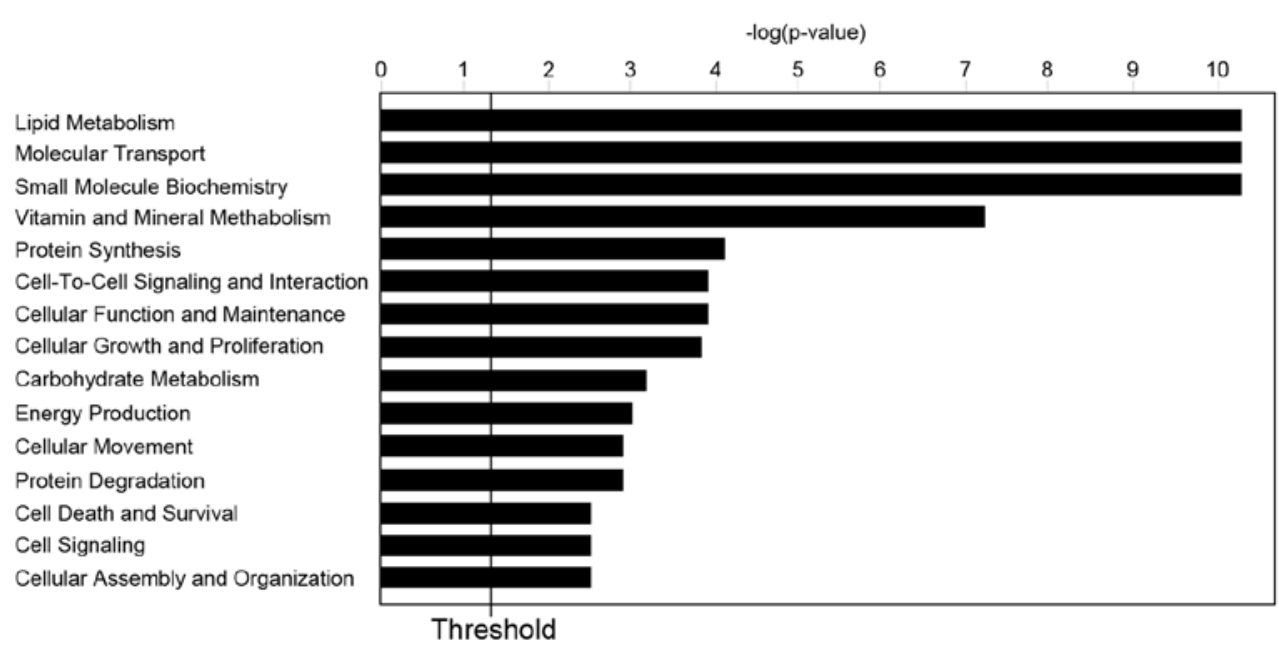

Figure 3. SW480-derived exosomes induce changes in gene expression in HepG2 cells. (A) Gene expression profiles of exosome-treated HepG2 cells (exosomes) and untreated HepG2 cells (control) after $24 \mathrm{~h}$. Microarray analysis was performed using a Toray 2-color mRNA microarray system using Cy3-labeled mRNAs from exosome-treated HepG2 cells and Cy5-labeled mRNAs from untreated HepG2 cells. Forty-five probes were upregulated and 42 probes were downregulated with magnitudes of $>1.50$-fold change in exosome-treated cells compared with untreated cells. (B) Relative expression of ACTA1, TAGLN, $F A B P 1$ and $F G G$ mRNAs in HepG2 cells after $24 \mathrm{~h}$ incubation with exosomes by RT-qPCR. GAPDH was used as an invariant control. Values were determined by the comparative $\mathrm{Ct}$ method and normalized using the values of control set at 1.0. Double asterisks (**) indicate significant differences from untreated HepG2 cells ( $<<0.01$, Student's t-test). (C) Predicted functional changes in HepG2 cells with exosome treatment using the Ingenuity Pathway Analysis (IPA). Bar chart analysis was used for predictions. Horizontal axis shows - $\log _{10}$ (p-value) based on Fisher's Exact test to compare probe data with gene ontology. Threshold line represents $-\log _{10}(0.05)$. Longer bars indicate stronger associations with changes in function induced by exosome treatment.

performed a Toray 2-color mRNA microarray analysis. The mRNA profiles of HepG2 cells treated for $24 \mathrm{~h}$ with $10 \mathrm{ng} / \mu \mathrm{l}$ SW480-derived exosomes (exosomes) and untreated HepG2 cells (control) were compared by scatter plot analysis. As seen in Fig. 3A, 45 probes were upregulated by $>1.50$-fold and 42 probes were downregulated by $>1.50$-fold in HepG 2 cells treated with SW480-derived exosomes. ACTAl ( $\alpha$-actin-1) mRNA and TAGLN (Transgelin, smooth muscle protein 22- $\alpha$ ) mRNA were among those upregulated, while $F A B P 1$ (fatty acid-binding protein) mRNA and $F G G$ (fibrinogen $\gamma$ chain precursor) mRNA were among those downregulated in HepG2 cells incubated with SW480-derived exosomes. These results were validated by $\mathrm{RT}$-qPCR using the primer pairs included in Table I. The expression of ACTA1 mRNA and TAGLN mRNA in HepG2 cells treated with
SW480-derived exosomes was significantly upregulated by 1.86-fold $(\mathrm{p}=0.00011)$ and 1.94 -fold $(\mathrm{p}=0.00063)$, respectively, compared with controls (Fig. 3B). Moreover, FABPl mRNA and $F G G$ mRNA expression in treated HepG2 cells was significantly downregulated by 2.85 -fold $(\mathrm{p}=0.00012)$ and 2.30-fold $(\mathrm{p}=0.00003)$, respectively. These results indicated that the SW480-derived exosomes led to changes in the expression of several genes in HepG2 cells.

To predict the functional outcomes of SW480-derived exosome treatment in HepG2 cells, the ingenuity pathway analysis (IPA) was performed using the upregulated and downregulated genes detected by microarray analysis. The involvement of a cell movement pathway was predicted based on the IPA bar chart analysis (Fig. 3C). In addition, the lipid metabolism, molecular transport, and small molecule 
Table I. Primer sequences for RT-qPCR.

\begin{tabular}{|c|c|c|c|}
\hline Primer name & Sequence $\left(5^{\prime}-3^{\prime}\right)$ & Size (nt) & PCR products size $(\mathrm{bp})$ \\
\hline \multicolumn{4}{|l|}{ GAPDH } \\
\hline Forward & AGCCACATCGCTCAGACAC & 19 & \multirow[t]{2}{*}{66} \\
\hline Reverse & GCCCAATACGACCAAATCC & 19 & \\
\hline \multicolumn{4}{|l|}{ ACTAl } \\
\hline Forward & GACAGCGCCAAGTGAAGC & 18 & \multirow[t]{2}{*}{107} \\
\hline Reverse & CTTCGTCGCACATTGTGTCT & 20 & \\
\hline \multicolumn{4}{|l|}{$T A G L N$} \\
\hline Forward & GGCCAAGGCTCTACTGTCTG & 20 & \multirow[t]{2}{*}{74} \\
\hline Reverse & CCCTTGTTGGCCATGTCT & 18 & \\
\hline \multicolumn{4}{|l|}{$F A B P 1$} \\
\hline Forward & TGATCCAAAACGAATTCACG & 20 & \multirow[t]{2}{*}{90} \\
\hline Reverse & САCСТTCCAACTGAACCACTG & 21 & \\
\hline \multicolumn{4}{|l|}{$F G G$} \\
\hline Forward & AGAAGGTAGCCCAGCTTGAA & 20 & \multirow[t]{2}{*}{96} \\
\hline Reverse & TGGCAATGTCTTGACAATCTTT & 22 & \\
\hline
\end{tabular}

Table II. Predicted activation state of function by up-/down-regulated genes using IPA.

\begin{tabular}{|c|c|c|c|c|c|}
\hline Category & $\begin{array}{c}\text { Diseases or } \\
\text { functions annotation }\end{array}$ & $\mathrm{p}$-value & $\begin{array}{c}\text { Predicted } \\
\text { activation state }\end{array}$ & $\begin{array}{l}\text { Activation } \\
\text { z-score }\end{array}$ & Molecules \\
\hline Lipid metabolism & $\begin{array}{l}\text { Concentration of } \\
\text { triacylglycerol }\end{array}$ & 0.00031 & Decreased & -2.021 & $\begin{array}{l}\text { APOA1, APOA2, APOC3, } \\
\text { DGAT1, FABP1, MTTP }\end{array}$ \\
\hline Molecular transport & $\begin{array}{l}\text { Concentration of } \\
\text { triacylglycerol }\end{array}$ & 0.00031 & Decreased & -2.021 & $\begin{array}{l}\text { APOA1, APOA2, APOC3, } \\
\text { DGAT1, FABP1, MTTP }\end{array}$ \\
\hline Small molecule biochemistry & $\begin{array}{l}\text { Concentration of } \\
\text { triacylglycerol }\end{array}$ & 0.00031 & Decreased & -2.021 & $\begin{array}{l}\text { APOA1, APOA2, APOC3, } \\
\text { DGAT1, FABP1, MTTP }\end{array}$ \\
\hline
\end{tabular}

biochemistry pathways were strongly predicted by IPA bar chart analysis (Fig. 3C). The activation z-scores that predict the activation state were $-2.021(\mathrm{p}=0.00031)$ for the categories of lipid metabolism, molecular transport, and small molecule biochemistry of triacylglycerol (Table II). These values were a result of the downregulation of apolipoprotein A-I (APOA1), apolipoprotein A-II (APOA2), apolipoprotein C-III (APOC3), diacylglycerol O-acyltransferase 1 (DGAT1), fatty acid binding protein $1(F A B P 1)$ and microsomal triglyceride transfer protein $(M T T P)$ mRNAs, which suggested that SW480-derived exosomes could be involved in suppressing the lipid metabolism, molecular transport, and small molecule biochemistry of triacylglycerol in HepG2 cells. Overall, these results suggested that SW480-derived exosomes might induce multiple pathways in addition to the induction of HepG2 cell migration.

\section{Discussion}

The aim of this study was to investigate novel functions and characteristics of exosomes. Our results include several interesting findings: i) exosomes derived from SW480 cancer cells were taken up into HepG2 recipient cells via dynamindependent endocytosis and were localized to lysosomes; ii) SW480-derived exosomes induced the recipient cancer cell migration by activating the classical MAP kinase pathway; iii) these exosomes led to changes in the expression of several mRNAs in recipient HepG2 cells, and iv) these exosomes altered multiple functions in the recipient HepG2 cells.

Mathivanan et al reported that several proteins were expressed on exosomal membranes and proposed possible mechanisms for intercellular communications coordinated by exosomes (17). It is possible that an exosome-to-cell pathway based on ligand-to-receptor interactions was involved in initiating the signaling for enhanced cell migration in our study. Therefore, we determined the phosphorylation status of ERK1/2 in HepG2 cells that were incubated with SW480derived exosomes in the presence of dynasore (Fig. 2D). Our results indicated that ERK1/2 phosphorylation was induced by the uptake of exosomes via dynamin-dependent endocytosis. Future studies examining the interactions between exosomal membrane components and recipient cell receptors will be 
important as dynamin-dependent endocytosis is a receptormediated mechanism.

Kawamoto et al demonstrated that tumor-derived microvesicles were taken up into vascular endothelial cells via endocytosis (18). In our study, in agreement with those findings, we showed that dynamin-dependent endocytosis was involved in the uptake of exosomes by recipient cells (Fig. 1C). Further, we showed that these exosomes colocalized with the recipient cell lysosomes in as little as $30 \mathrm{~min}$ (Fig. 1D). This suggests that exosomes taken up into the target cell are destined for degradation.

Recently, exosomal microRNAs have attracted considerable attention. The increases in cell migration in vitro by exosomes in the present study are unlikely to be mediated by exosomal microRNAs because activation of the classical MAP kinase pathway occurred within $10 \mathrm{~min}$ after incubation with SW480-derived exosomes. However, exosomal microRNAs may play important roles in regulating cell migration and/or invasion within the cancer microenvironment in vivo. Krijger et al reported that miR-21 suppressed the translation of phosphatase and tensin homolog (PTEN) and programmed cell death 4 (PDCD4) mRNA in colorectal cancers (19). The expression of miR-21 was shown to increase in colorectal cancers, while cancer metastasis was regulated by suppressing PTEN and PDCD4 (20,21). It is possible that exosomal microRNAs involved in cancer malignancy were involved in the suppression of protein translation in target HepG2 cells in our study. Therefore, it will be necessary to analyze the functions of microRNAs, including miR-21, in HepG2 cells exposed to SW480-derived exosomes.

Cancer cells naturally interact with adjacent normal cells in vivo, and the malignancy and suppression of cancer cells are regulated by various signals derived from adjacent cancer cells as well as from normal cells. Thus, it will be necessary to determine the functional roles of exosomes secreted from both cancer and normal cells within the cancer microenvironment.

\section{Acknowledgements}

This study was supported in part by a Hirosaki University Institutional Research Grant for Young Scientists, KAKENHI (no. 23790613) Grant-in-Aid for Young Scientists (B), a grant from KAKENHI (no. 25670264) for Challenging Exploratory Research, a grant from the Suzuken Memorial Foundation (no. 11-076), a grant from the Takeda Science Foundation, and a grant from the Ministry of Education, Culture, Sports, Science and Technology of Japan (MEXT).

\section{References}

1. Karlsson M, Lundin S, Dahlgren U, Kahu H, Pettersson I and Telemo E: 'Tolerosomes' are produced by intestinal epithelial cells. Eur J Immunol 31: 2892-2900, 2001.

2. Muturi HT, Dreesen JD, Nilewski E, Jastrow H, Giebel B, Ergun S and Singer BB: Tumor and endothelial cell-derived microvesicles carry distinct CEACAMs and influence T-cell behavior. PLoS One 8: e74654, 2013.

3. King HW, Michael MZ and Gleadle JM: Hypoxic enhancement of exosome release by breast cancer cells. BMC Cancer 12: 421, 2012.
4. Montecalvo A, Larregina AT, Shufesky WJ, Stolz DB, Sullivan ML, Karlsson JM, Baty CJ, Gibson GA, Erdos G, Wang Z, et al: Mechanism of transfer of functional microRNAs between mouse dendritic cells via exosomes. Blood 119: 756-766, 2012.

5. Lee JK, Park SR, Jung BK, Jeon YK, Lee YS, Kim MK, Kim YG, Jang JY and Kim CW: Exosomes derived from mesenchymal stem cells suppress angiogenesis by down-regulating VEGF expression in breast cancer cells. PLoS One 8: e84256, 2013.

6. Escola JM, Kleijmeer MJ, Stoorvogel W, Griffith JM, Yoshie O and Geuze HJ: Selective enrichment of tetraspan proteins on the internal vesicles of multivesicular endosomes and on exosomes secreted by human B-lymphocytes. J Biol Chem 273: 20121-20127, 1998.

7. Pan BT and Johnstone RM: Fate of the transferrin receptor during maturation of sheep reticulocytes in vitro: Selective externalization of the receptor. Cell 33: 967-978, 1983.

8. Valadi H, Ekström K, Bossios A, Sjöstrand M, Lee JJ and Lötvall JO: Exosome-mediated transfer of mRNAs and microRNAs is a novel mechanism of genetic exchange between cells. Nat Cell Biol 9: 654-659, 2007.

9. Zhang Y, Liu D, Chen X, Li J, Li L, Bian Z, Sun F, Lu J, Yin Y, Cai X, et al: Secreted monocytic miR-150 enhances targeted endothelial cell migration. Mol Cell 39: 133-144, 2010.

10. Hakulinen J, Sankkila L, Sugiyama N, Lehti K and Keski-Oja J: Secretion of active membrane type 1 matrix metalloproteinase (MMP-14) into extracellular space in microvesicular exosomes. J Cell Biochem 105: 1211-1218, 2008.

11. Janowska-Wieczorek A, Wysoczynski M, Kijowski J, MarquezCurtis L, Machalinski B, Ratajczak J and Ratajczak MZ: Microvesicles derived from activated platelets induce metastasis and angiogenesis in lung cancer. Int J Cancer 113: 752-760, 2005.

12. Zhu W, Huang L, Li Y, Zhang X, Gu J, Yan Y, Xu X, Wang M, Qian $\mathrm{H}$ and $\mathrm{Xu}$ W: Exosomes derived from human bone marrow mesenchymal stem cells promote tumor growth in vivo. Cancer Lett 315: 28-37, 2012.

13. Ristorcelli E, Beraud E, Verrando P, Villard C, Lafitte D, Sbarra V, Lombardo D and Verine A: Human tumor nanoparticles induce apoptosis of pancreatic cancer cells. FASEB J 22: 3358-3369, 2008.

14. Chiba M, Kimura M and Asari S: Exosomes secreted from human colorectal cancer cell lines contain mRNAs, microRNAs and natural antisense RNAs, that can transfer into the human hepatoma HepG2 and lung cancer A549 cell lines. Oncol Rep 28: 1551-1558, 2012.

15. Wang E, Zhao M, Forrester JV and McCaig CD: Electric fields and MAP kinase signaling can regulate early wound healing in lens epithelium. Invest Ophthalmol Vis Sci 44: 244-249, 2003.

16. Kang ES, Oh MA, Lee SA, Kim TY, Kim SH, Gotoh N, Kim YN and Lee JW: EGFR phosphorylation-dependent formation of cell-cell contacts by Ras/Erks cascade inhibition. Biochim Biophys Acta 1773: 833-843, 2007.

17. Mathivanan S, Ji H and Simpson RJ: Exosomes: Extracellular organelles important in intercellular communication. J Proteomics 73: 1907-1920, 2010.

18. Kawamoto T, Ohga N, Akiyama K, Hirata N, Kitahara S, Maishi N, Osawa T, Yamamoto K, Kondoh M, Shindoh M, et al: Tumor-derived microvesicles induce proangiogenic phenotype in endothelial cells via endocytosis. PLoS One 7: e34045, 2012.

19. de Krijger I, Mekenkamp LJ, Punt CJ and Nagtegaal ID: MicroRNAs in colorectal cancer metastasis. J Pathol 224: 438-447, 2011.

20. Meng F, Henson R, Wehbe-Janek H, Ghoshal K, Jacob ST and Patel T: MicroRNA-21 regulates expression of the PTEN tumor suppressor gene in human hepatocellular cancer. Gastroenterology 133: 647-658, 2007.

21. Asangani IA, Rasheed SA, Nikolova DA, Leupold JH, Colburn NH, Post S and Allgayer H: MicroRNA-21 (miR-21) post-transcriptionally downregulates tumor suppressor Pdcd4 and stimulates invasion, intravasation and metastasis in colorectal cancer. Oncogene 27: 2128-2136, 2008. 